\title{
Aislamiento y caracterización del virus de la diarrea viral bovina en un ternero con síndrome purpúrico ${ }^{\#}$
}

\author{
Characterization of bovine viral diarrhea virus isolated from cattle \\ with hemorrhagic syndrome
}

\author{
A Gollán ${ }^{1}$, S A Chimeno Zoth ${ }^{2}$, M E Piccone ${ }^{* 2}$, B Mariño ${ }^{1}$, C Peralta ${ }^{1}$, R Rodríguez Armesto ${ }^{3}$, H Occhi ${ }^{1}$. \\ ${ }^{1}$ Facultad de Ciencias Veterinarias (UNL). Padre Kreder 2805, Esperanza, CP 3080, Santa Fe, Argentina. \\ ${ }^{2}$ Instituto de Biotecnología, CICVyA, INTA, CC 77 (1708) Morón, Buenos Aires, Argentina. \\ ${ }^{3}$ Hospital de Salud Animal, Facultad de Ciencias Veterinarias, Universidad Nacional del Litoral (UNL), Argentina.
}

\section{SUMMARY}

The Bovine Viral Diarrhea (BVDV) virus causes numerous pathologies that range from reproductive losses to infections of little clinical significance in the bovine digestive tract. Variation have been reported among the strains of the BVDV, which are classified into two biotypes; cytopathogenic (CP) and non-cytopathogenic (NCP), and the viral types I and II. This work describes the pathological findings in a calf with diarrhea and severe thrombocytopenia. The strain isolated (334/3) was molecularly characterized by sequencing of the 5'non-coding region (5' NCR). These analyses revealed 90-98\% homologies with reference strains type I strains and the changes associated with BVDV type II, were not found.

Palabras clave: DVB, caracterización molecular.

Key words: BVDV, molecular characterization, types, tombocytopenia.

\section{INTRODUCCION}

La Diarrea Viral Bovina (DVB) es una enfermedad económicamente importante que afecta al ganado bovino y que afecta a numerosos países (Houe 1999). En Argentina, la enfermedad se encuentra ampliamente difundida en la región de la cuenca lechera santafesina, ubicada en la pampa húmeda, zona de intensa actividad agrícola-ganadera, como lo señalan trabajos previos realizados para la detección de anticuerpos en rodeos lecheros (Occhi y col 1991) y la prevalencia serológica descrita por otros autores (Muñoz y col 1996).

La enfermedad se puede presentar en distintas formas, que van desde una subclínica a clínica hiperaguda o aguda hasta una crónica, acompañada por inmunodepresión que incrementa la susceptibilidad a patógenos secundarios. En su forma aguda, produce abortos, muertes perinatales, nacimientos prematuros y un amplio rango de malformaciones (Duffel y col 1986). En su forma crónica da lugar al nacimiento de animales persistentemente infectados (P.I.) e inmunotolerantes al virus (Bolin y Ridpath 1992), los

Aceptado: 22.11.2005.

\# Este trabajo fue subsidiado por un proyecto de CAI+D 25-167 (A Gollan, UNL) y un proyecto SECyT-PICT 97 08-00067-01290 (ME Piccone, INTA).

* Dirección actual ARS, PIADC, USDA PO Box 848 Greenport NY 11944-USA, Fax 631-323-3006 mpiccone@piadc.ars.usda.gov cuales resultan de gran relevancia epidemiológica y son los responsables de la perpetuación del virus en la población bovina (Edwards y col 1987).

Las cepas del VDVB presentan dos biotipos, no citopatogénicos (NCP) y citopatogénico (CP), diferenciables por el efecto que causan en cultivos celulares susceptibles in vitro (Clarke y col 1987). Dicha citopatogenicidad es una propiedad que depende tanto de los factores genéticos del virus como de los del cultivo celular utilizado. Se considera que el biotipo CP podría derivar del NCP por efectos de mutaciones y recombinaciones (Bolin y col 1992, Collet 1992). Estudios genéticos han demostrado que las mutaciones y rearreglos dentro de la región que codifica para la proteína no estructural p125 (p54/p80) están relacionados con la conversión del VDVB NCP a CP (Meyers y col 1992).

Desde el año 1980 se han descrito aislamientos del VDVB capaces de causar una enfermedad aguda en el ganado inmunocompetente con un síndrome caracterizado por hemorragias equimóticas en las mucosas de varios órganos, siendo el rasgo distintivo de esas infecciones una severa trombocitopenia responsable de las lesiones observadas (Corapi y col 1989, Rebhun y col 1989). Los aislamientos identificados, capaces de inducir la enfermedad aguda, pertenecen a un linaje genético distinto del VDVB designado como genotipo II. La comparación de secuencias de la región 5' no codificante (5' RNC) del genoma revela un $75 \%$ de homología con los 
genotipos I de los aislamientos del VDVB (Pellerin y col 1994, Odeón y col 1999). Las cepas del VDVB se agrupan en dos genotipos diferentes, las de presentación clásica o VDVB I y las cepas muy virulentas o VDVB II responsables de producir trombocitopenia, hemorragias, fiebre, diarrea y muerte. La diferenciación entre ambos tipos se realiza a través de estudios moleculares, basados en el análisis filogenético de la región 5' no-codificante estrechamente relacionada con la patogenia y el tropismo de la enfermedad (Ridpath y col 2000, Evermann y Ridpath 2002, Toplak y col 2004, Wakeley y col 2004).

El virus de la DVB pertenece al Género Pestivirus de la Familia Flaviviridae. El genoma viral consiste en una molécula de ARN de cadena simple y polaridad positiva de aproximadamente $12,5 \mathrm{~Kb}$, que puede dividirse en tres regiones: una región 5 ' no codificante $(5$ ' RNC), altamente conservada, que contiene un sitio interno de entrada a los ribosomas (IRES), una región codificante que contiene un único marco de lectura abierto y una región 3' no codificante (3' RNC) (figura 1A).

En el presente trabajo se describen los hallazgos patológicos encontrados en un ternero muerto con síndrome purpúrico y la caracterización molecular de la cepa viral aislada (denominada 333/4).

\section{MATERIAL Y METODOS}

ANIMALES. ASPECTOS CLINICO-PATOLOGICOS DEL CASO. En un rebaño lechero del departamento de San Cristóbal de la provincia de Santa Fe (Argentina) murieron 5 ter- neros menores de 15 días debido a un síndrome diarreico disentérico. Dichos animales habían sido sometidos, aunque $\sin$ respuesta favorable, a tratamientos sintomáticos instaurados, tales como antibióticoterapia, quimioterapia, corticoterapia y fluidoterapia. Se realizó un hemograma completo a dos terneros con idéntica signología clínica, encontrándose una marcada plaquetopenia $\left(37.000 / \mathrm{mm}^{3}\right.$, Valor Normal de referencia: $\left.500.000 / \mathrm{mm}^{3}\right)$ y leucopenia $\left(3.806 / \mathrm{mm}^{3}\right.$, Valor de referencia: $10.525 / \mathrm{mm}^{3}$ ). Posteriormente, uno de los terneros afectados fue derivado al Hospital de Salud Animal de la Facultad de Ciencias Veterinarias de la Universidad Nacional del Litoral para su necropsia.

Se constató un síndrome purpúrico generalizado, constituido por petequias y esquimosis, siendo más destacado en lengua, paladar duro, esófago, abomaso, placas de Peyer, mucosa de intestino delgado y grueso (figura 2). Se detectaron, además, lesiones erosivas ulcerativas longitudinales, de difícil visualización, en esófago, abomaso, píloro, intestinos delgado (ID) y grueso (IG). Los nódulos linfáticos mesentéricos se encontraron aumentados de tamaño y edematosos. El contenido del intestino fue sanguinolento, líquido en el ID y en forma de boñigas en el IG. Se encontró tejido linfoideo fácilmente visible alrededor de la válvula ileocecal y en los nódulos de la submucosa de colon ascendente.

Al momento de la necropsia se obtuvieron muestras en formol tamponado $10 \%$ y en medio de transporte Minimun Essential Medium (MEM) de nódulos linfáticos mesentéricos, hígado, abomaso, timo, tiroides y riñón,

$1 \mathrm{~A}$

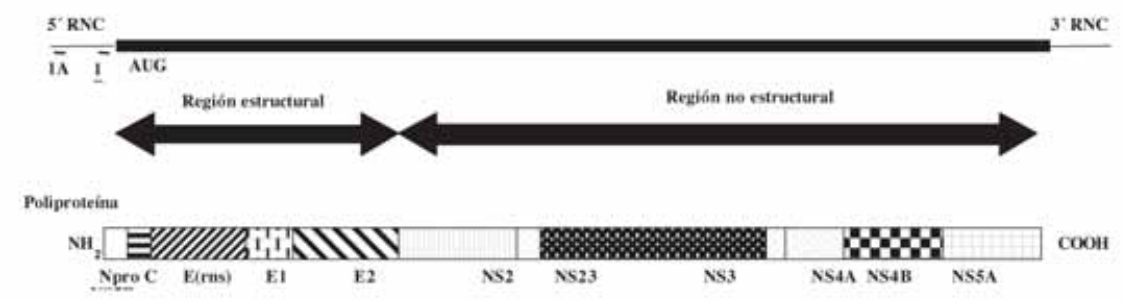

$1 \mathrm{~B}$

\begin{tabular}{|c|c|c|}
\hline $\begin{array}{l}\text { Nombre del } \\
\text { Oligonucleótido }\end{array}$ & Secuencia & Orientación \\
\hline $\begin{array}{l}1 \mathrm{~A} \\
1 \mathrm{~B}\end{array}$ & 5' GAGGCTAGCCATGCCCTTAGT $3^{\prime}$ & Positiva \\
\hline
\end{tabular}

Figura 1. Amplificación de la región 5' no codificante. Parte A: Diagrama del genoma del VDVB indicando las regiones 5' y 3' no codificantes (5' RNC y 3' RNC, respectivamente), las proteínas estructurales y no estructurales. Se señala la región amplificada. Parte B: Detalle de los oligonucleótidos utilizados en la reacción de PCR.

PCR amplification of the BVDV 5' untranslated region. A: Diagram of the genome of the BVDV showing the 5' and 3' untranslated region (5'UTR and 3'UTR, respectively), the non-structural and the structural proteins regions. The PCR target region is indicated. B: Detail of the primers used for PCR reaction. 

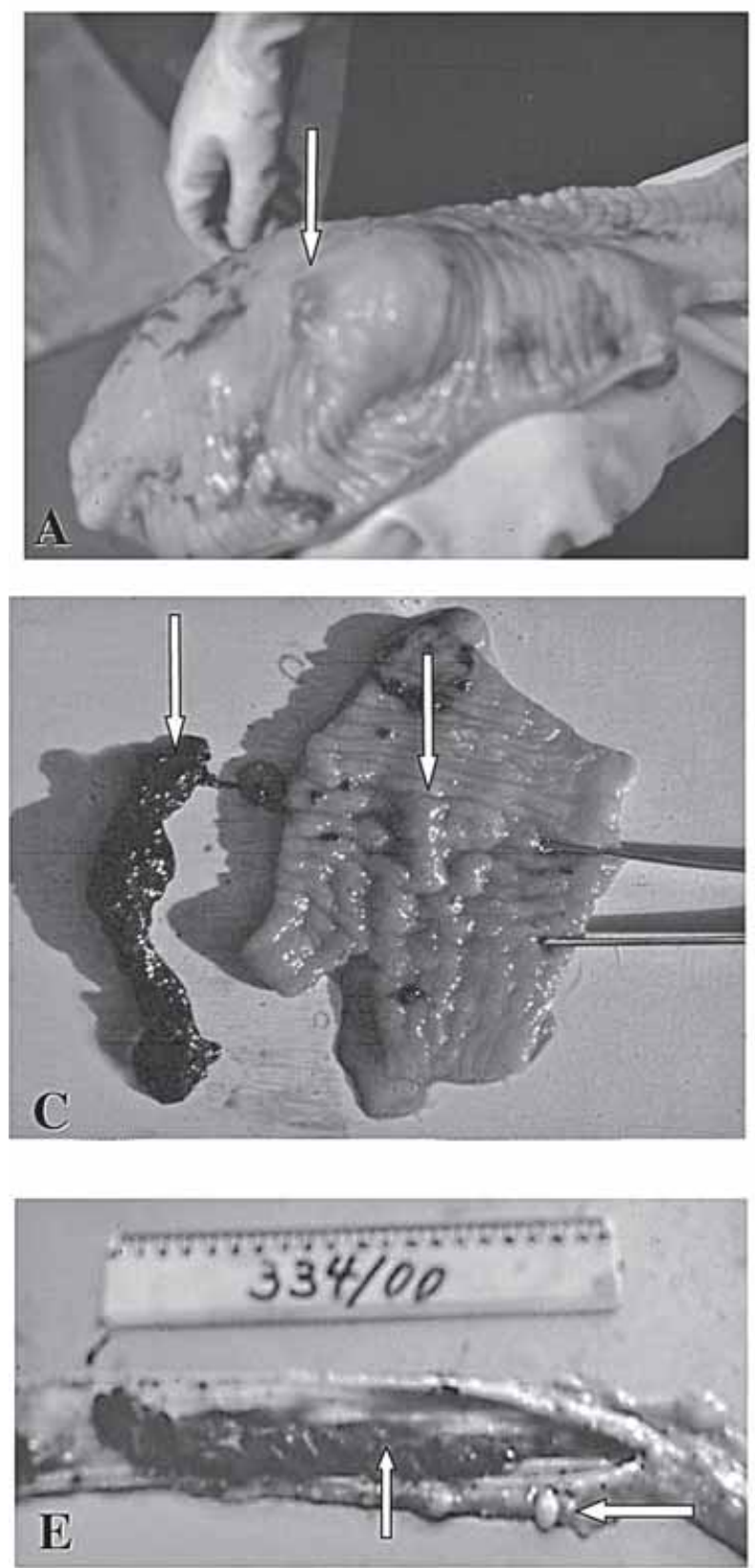
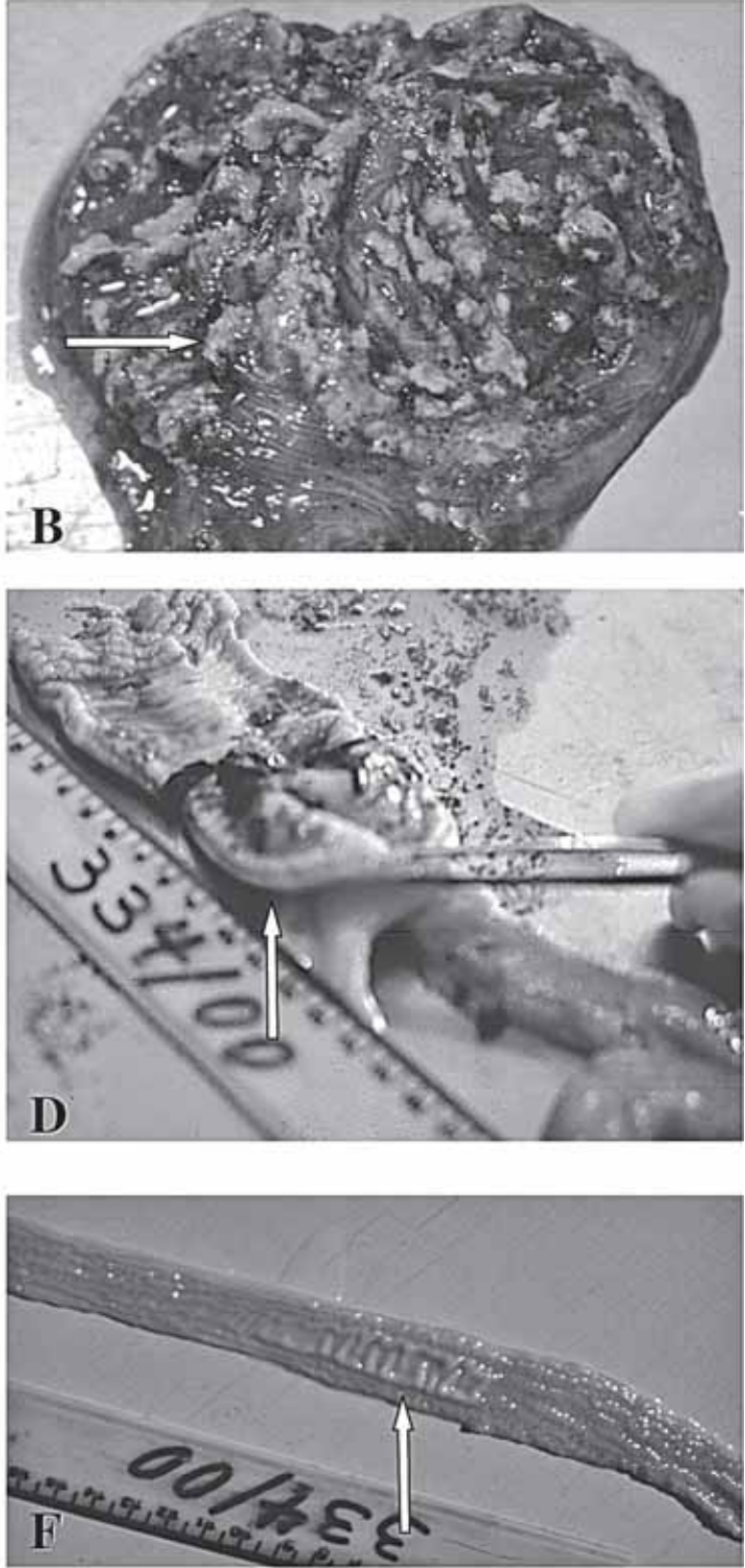

Figura 2. Lesiones asociadas a la cepa del VDVB 333/4. Panel A, válvula ileocecal hemorrágica con tejido linfoideo perivalvular aumentado. Panel B, gastritis hemorrágica aguda con presencia de pseudomembranas. Panel C, contenido sanguinolento en el lumen intestinal, tejido linfoideo de la mucosa del colon ascendente evidente. Panel D, edema de la pared del colon ascendente y contenido sanguinolento en la luz intestinal. Panel E, colon descendente con contenido sanguinolento y nódulo mesentérico aumentado de tamaño. Panel F, yeyuno con aumento de tamaño de las placas de Peyer.

Lesions associated with BVDV strain 333/4. Panel A, hemorrhagic ileo-caecum valve with lymphoid tissue increased. Panel B, acute hemorrhagic gastritis with pseudo membranes. Panel C, hemorrhagic fluids in the intestinal lumen, and enlarged lymph nodes in the colon. Panel $\mathrm{D}$, colon with edema and hemorrhagic fluid in the intestinal lumen. Panel E, hemorrhagic fluid in the colon and enlarged mesenteric lympho nodes. Panel F, Peyer's patches of the jejunum are greatly enlarged.

para su posterior procesamiento histológico y aislamiento viral.

AISLAMIENTO VIRAL. Trozos de cada órgano se cortaron finamente con tijera y se trituraron en un mortero con arena estéril. Los triturados fueron resuspendidos en medio de cultivo MEM con el agregado de solución de antibiótico-antimicótico (GIBCO) al $1 \%$ y en una relación del 10\% de medio sobre volumen de órganos. Estas suspensiones se filtraron por gasa y posteriormente se centrifugaron a $3.000 \mathrm{rpm}$ por $20 \mathrm{~min}$ a $4^{\circ} \mathrm{C}$. Se controlaron bacteriológicamente en medios de tioglicolato y glucosado de Saboureau (Britania) y se almacenaron a $-85^{\circ} \mathrm{C}$ hasta su inoculación en cultivo celular. 
El aislamiento primario se realizó en la línea celular establecida MDBK (Madin Darby Bovine Kidney), obtenida del Banco Argentino de Células (ABAC) en calidad de certificada como libre de VDVB. Se utilizó MEM suplementado con $10 \%$ de suero fetal bovino (SFB, Gibco) y $1 \%$ de antibiótico-antimicótico, como medio de crecimiento (MC) y el mismo medio exento de SFB como medio de mantenimiento (MM). Las infecciones se efectuaron según metodologías de rutina. Se utilizaron tres muestras de cada órgano y se realizaron 4 pasajes ciegos.

Los sobrenadantes de los cultivos infectados que evidenciaron efecto citopático (ECP) se centrifugaron a $5.000 \mathrm{rpm}$ por 20 minutos a fin de decantar los detritos celulares y se realizaron ensayos de neutralización viral (NT) e inmunofluorescencia directa (IFD).

\section{IDENTIFICACION DEL AISLAMIENTO}

Neutralización viral (NT). Se realizó a partir de los sobrenadantes provenientes de cultivos infectados que desarrollaron ECP. Este ensayo se realizó con un suero positivo de referencia, en su forma suero constante/virus variable (Manual de Técnicas de Diagnostico Virológico, FAO 1988) en cuatro réplicas por dilución probada desde $10^{1}$ a $10^{10}$, enfrentando antisuero en dilución $1 / 20$ en monocapas de células MDBK sembradas en placas de 96 pocillos. Para determinar la neutralización del aislamiento, se definió el punto máximo de la infectividad, como la máxima dilución probada que logró ser completamente neutralizada por el antisuero $\left(10^{5}\right)$, comparándose la integridad celular con la de los controles.

Inmunofluorescencia directa (IFD). Se realizó según el procedimiento original de Coons y col (1971) (Manual de Técnicas de Diagnóstico Virológico, FAO 1988). Las células infectadas se desprendieron de sus soportes antes de alcanzar el $100 \%$ de ECP, se lavaron con PBS y se ajustó la concentración a $10^{5} \mathrm{cél} / \mathrm{ml}$. Se realizaron improntas por duplicado en portaobjetos grabados. Estas se fijaron e incubaron con el anticuerpo anti-VDVB conjugado con isotiocianato de fluoresceína, según las indicaciones del fabricante (VMRD). Se observó la clásica fluorescencia citoplasmática característica del virus en estudio. Todos los pasajes positivos por ECP se confirmaron por IFD.

\section{TECNICAS HISTOLOGICAS}

Los órganos se fijaron en formol tamponado al $10 \%$ y posteriormente se realizó la deshidratación e inclusión en parafina. Los cortes de $5 \mu \mathrm{m}$ realizados en un micrótomo tipo Minot se colorearon con hematoxilinaeosina, para su observación al microscopio óptico.
AMPLIFICACION POR RT-PCR Y SECUENCIACION

La región 5' no codificante del genoma viral se amplificó mediante la técnica de transcripción reversa asociada a la reacción en cadena de la polimerasa (RT-PCR) y posteriormente se realizó la secuenciación nucleotídica utilizando oligonucleótidos específicos. Brevemente, el ARN total extraído por el método del TRIzol (GibcoLife Technologies) a partir de células MDBK infectadas fue utilizado como templado para la síntesis de ADN complementario (ADNc) en presencia de $200 \mathrm{U}$ de transcriptasa reversa y $0,5 \mu \mathrm{g}$ de hexanucleótidos (Promega). Para la reacción de amplificación de la región 5' no codificante se utilizaron oligonucleótidos específicos (figura 1, panel B). Los productos de PCR se analizaron en geles de agarosa $1 \%$ y se purificaron utilizando el kit PCR Concert ${ }^{\circledR}$ (Gibco BRL).

Las secuencias nucleotídicas se determinaron por secuenciación cíclica utilizando $\left[\alpha{ }^{35} \mathrm{~S}\right]$ dATP (New England Biolabs) y el kit fmol ${ }^{\circledR}$ (Promega). Las secuencias nucleotídicas determinadas fueron alineadas y comparadas entre sí y con las secuencias de las cepas patrones reportadas en la bibliografía (Pellerin y col 1994), utilizando el programa DNAsis ${ }^{\circledR}$. El alineamiento múltiple de secuencias se llevó a cabo con el programa CLUSTAL X Multiple Sequence Alignment Program (versión 1.81, 2000-Thompson y col 1997). La creación del árbol filogenético se realizó con los programas DNADIST y NEIGHBOUR del paquete de programas PHYLIP (Phylogeny Inference Package) versión 3.5c @ (Felsenstein 1993). La presentación del árbol se realizó con el programa TREEVIEW@ versión 1.5.2. (Page 1996).

\section{RESULTADOS Y DISCUSION}

El presente estudio se llevó a cabo para evaluar la presencia del VDVB tipo II en la cuenca lechera santafesina, debido a que los animales presentaban un cuadro clínico semejante al descrito para dicho genotipo.

Los cultivos celulares infectados mostraron ECP compatible con el producido por el VDVB (vacuolación intensa, alteración y lisis celular), en todos los pasajes (P1P4) y en todos los tubos inoculados. La prueba de neutralización resultó positiva, y los aislamientos virales fueron neutralizados por el antisuero hasta la dilución $10^{-5}$. La IFD fue consistente, observándose claramente fluorescencia citoplasmática (dato no mostrado).

OBSERVACIONES HISTOPATOLOGICAS. Todas las lesiones coincidieron con las descritas para las cepas tipo II o trombocitopénicas (Corapi y col 1989, Broes y col 1992, Kobrak y Weber 1997, Odeon y col 1999). El examen histopatológico demostró en los nódulos linfáticos una linfoadenitis aguda hiperplásica, en bazo una esplenitis aguda, en hígado se observó una hepatitis intersticial 


\section{A}

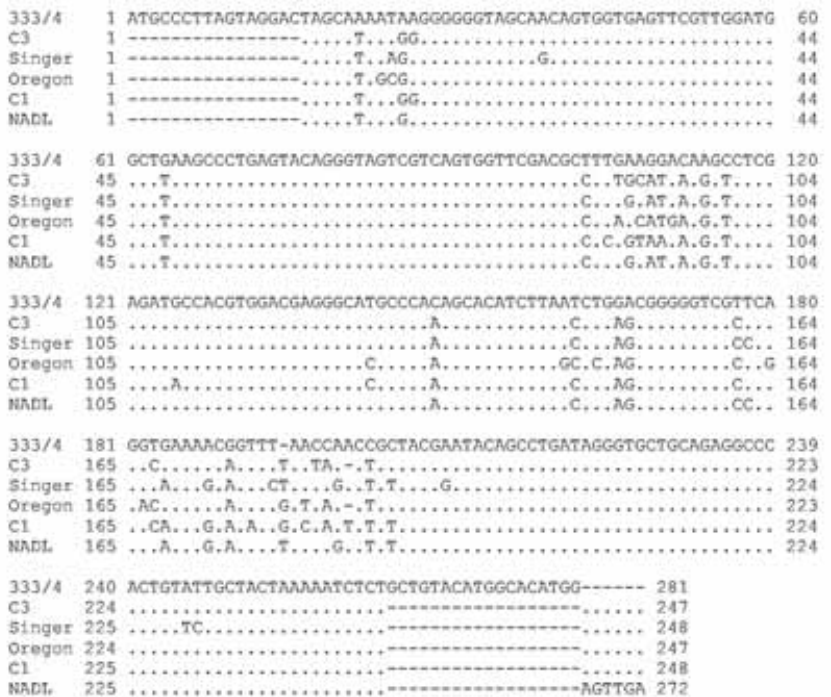

B

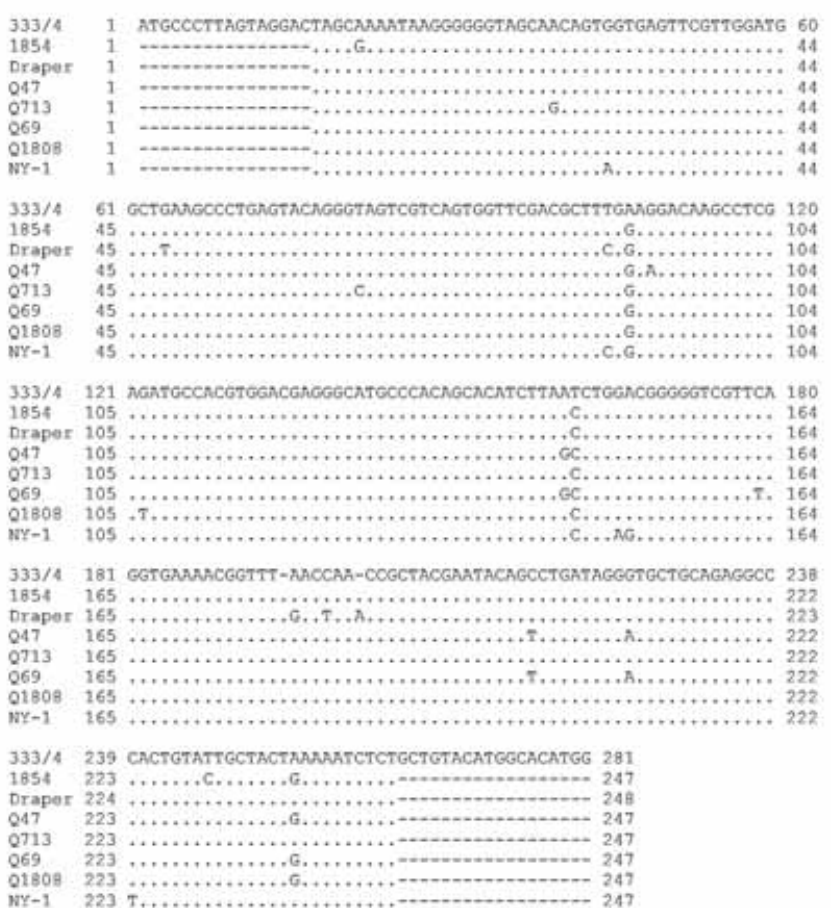

C

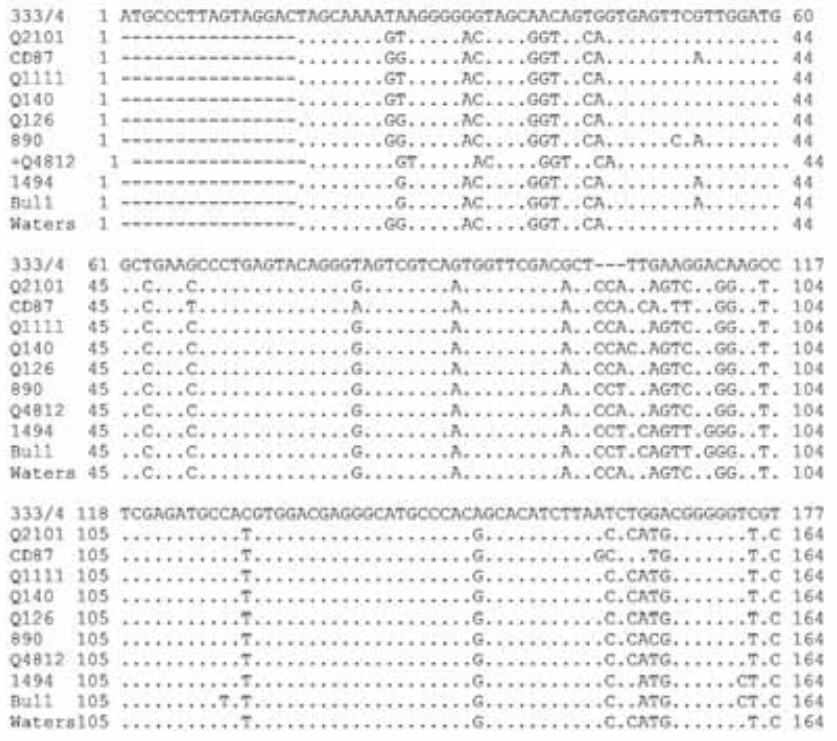

333/4 178 TCAGGTGAMACGGTIT-ANCCAACCGCTMCEMTACAGCCTGATAGGGTGCTGCAGMGG 236

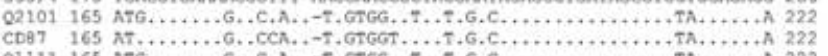

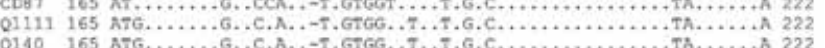

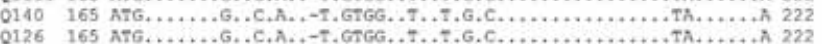

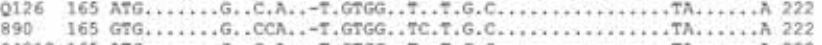
09612 165 .

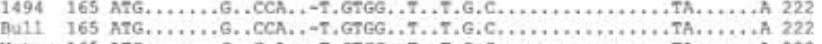

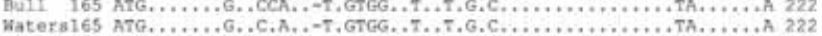

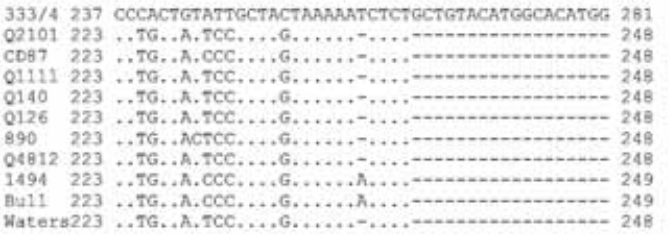

Figura 3. Comparación de la secuencia nucleotídica de la región 5' no codificante determinada por los oligonucleótidos IA y IB de la cepa aislada (333/4) con cepas integrantes de los grupos genotípicos Ia (A), Ib (B) y II (C) del VDVB. (.) sin cambio, (-) sin determinar

Comparison of nucleotide sequence of the 5' UTR from strain (333/4) and strains representatives of BVDV genotypic groups Ia (A), Ib (B) and II (C). (.) No change, (-) undetermined.

mononuclear con escasos cambios degenerativos. El abomaso presentó una inflamación catarral, la válvula ileocecal y el intestino delgado presentaron una enteritis mononuclear con hiperplasia de folículos linfoideos. La muestra de riñón reveló una nefritis glomerular exudativa con escasos cambios tubulares.
CARACTERIZACION MOLECULAR. La figura 3 muestra los resultados obtenidos de la secuenciación de la región 5' no codificante de la cepa aislada de los casos clínicos (333/4), y su comparación con cepas de referencia representantes de los grupos genotípicos Ia, Ib y II. El análisis de las secuencias reveló un $98 \%$ de similitud entre la cepa 


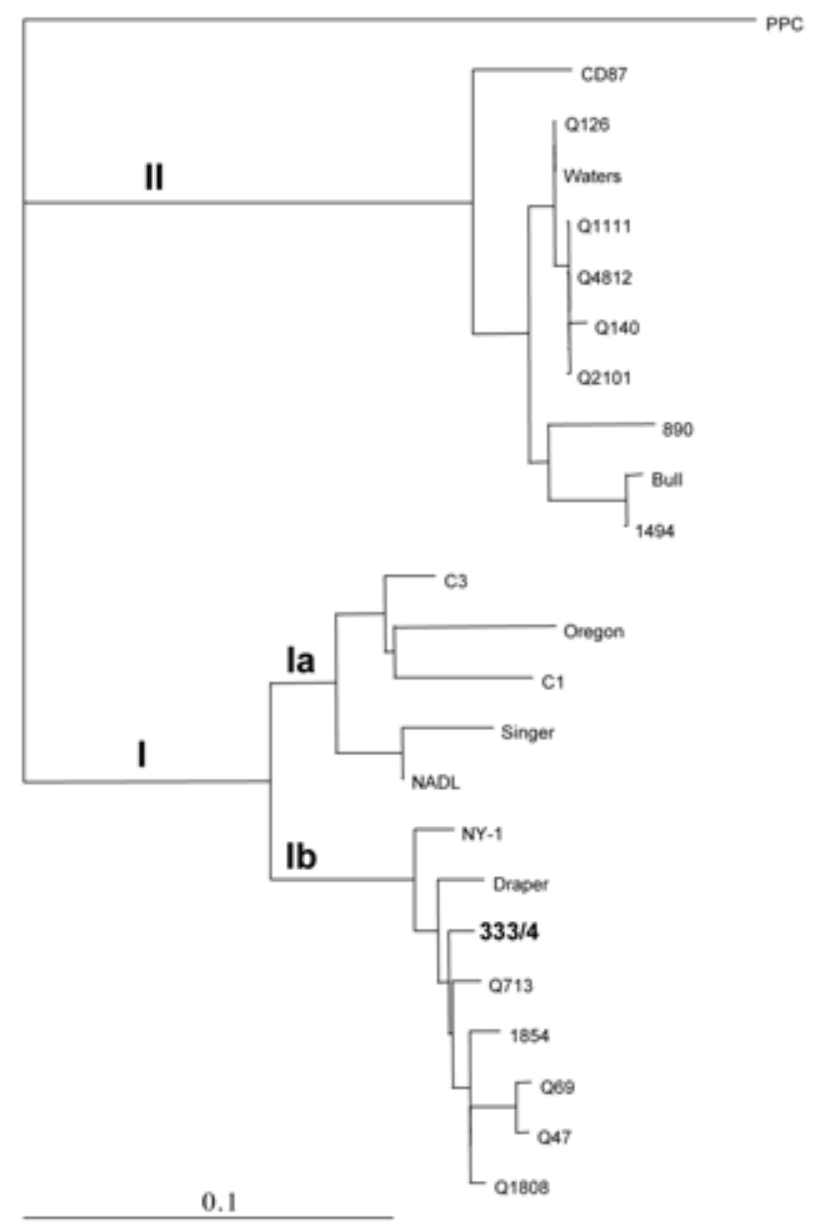

Figura 4. Arbol filogenético realizado por el método de Neighbour joining. Las matrices de distancia fueron confeccionadas a partir del algoritmo de Kimura de dos parámetros.

Neighbour-joining phylogenetic tree based on the BVDV 5' UTR sequences. Evolutionary distances were calculated by the Kimura 2-parameters algorithm.

aislada y las pertenecientes al grupo genotípico Ib y un $90 \%$ respecto de las del grupo Ia. De la comparación con el grupo II sólo se obtuvo un $76 \%$ de similitud. Asimismo, el análisis filogenético reveló que la secuencia correspondiente a la cepa 333/4 agrupa con las pertenecientes al grupo Ib (figura 4).

Estudios de genética molecular del virus han informado diferencias del $25-40 \%$ en la secuencia nucleotídica de la región 5' no codificante del genoma viral entre ambos genotipos (Pellerin y col 1994). Sin embargo, la secuencia nucleotídica de la región 5' no codificante de la cepa 333/4 reveló un $98 \%$ de similitud con cepas pertenecientes al grupo Ib. No se encontraron cambios de base asociados a BVDV tipo II informados en la bibliografía. Estos resultados sugieren que la presentación hemorrágica-trombocitopénica de la enfermedad puede ser inducida por el VDVB tipo I. Por lo que los síntomas clínicos no serían indicativos del genotipo del VDVB actuante (Wolfmeyer y col 1997, Hamers y col 2000). Sin embargo, no puede descartarse que en la cepa 333/4 alguna otra región genómica esté involucrada en la presentación del cuadro hemorrágico, o que dicha cepa sea el resultado de recombinaciones de cepas de ambos tipos circulantes en la región. La secuenciación de otras regiones del genoma aportará más información al respecto.

\section{AGRADECIMIENTOS}

Loa autores agradecen la colaboración del Dr. Guido König (INTA) en la construcción de los árboles filogenéticos.

\section{RESUMEN}

El Virus de la Diarrea Viral Bovina (VDVB) produce en el ganado bovino numerosas patologías que van desde pérdidas reproductivas hasta afecciones de poca significación clínica en el aparato digestivo. Se ha reportado variabilidad entre las cepas de VDVB, que se manifiesta por la existencia de los biotipos citopatogénicos (CP) y no citopatogénicos (NCP), y los tipos virales I y II. El presente trabajo describe los hallazgos patológicos y virológicos en un ternero que clínicamente exhibió trombocitopenia y diarrea. La cepa viral aislada (334/3) fue caracterizada molecularmente por secuenciación de la región 5' no-codificante (5' RNC). Los análisis realizados revelaron un 90-98\% de homología con las cepas de referencia tipo I, no encontrándose cambios asociados a las cepas VDVB tipo II.

\section{REFERENCIAS}

Bolin SR, J Ridpath. 1992. Differences in virulence between two noncytopathic bovine viral diarrhea virus in calves. Am J Vet Res 53, 2157-2163.

Broes A, G Wellemans, J Dheendene. 1992. Syndrome hémorragique chez des bovins infectés par le virus de la diarrhée virale bovine. Ann Méd Vét 137, 33-38.

Clarke MC, J Brownlie, CJ Howard. 1987. Isolation of cytopathic and non-cytopathic bovine viral diarrhea virus from tissues of infected animals. In: Pestivirus Infections of Ruminants. Edited by J.W. Harkness. Commission of the European Communities, Report EUR 10238. Pp 3-10.

Collett MS. 1992. Molecular genetics of pestiviruses. Comp Immunol Micro Infect Dis 15, 145-154.

Coons AH. 1971. The development of immunohistochemistry. Ann NY Acad Sci 177, 5-9.

Corapi WV, TW French, EJ Dubovi. 1989. Severe thrombocytopenia in young calves experimentally infected with non-cytopathic bovine viral diarrhea virus. $J$ Virol 63, 3934-3943.

Duffel SJ, MW Sharp, D Bates. 1986. Financial loss resulting from BVD-MD virus infection in a dairy herd. Vet Rec 118, 38-39.

Edwards S, TW Drew, SE Bushnell. 1987. Prevalence of bovine virus diarrhea virus viraemia. Vet Rec 120, 71.

Evermann JF, JF Ridpath. 2002. Clinical and epidemiologic observations of bovine viral diarrhea virus in the northwestern United States.. Vet Microbiol 89, 129-139. 
FAO (Organización de las Naciones Unidas para la Agricultura y la Alimentación) Red de cooperación Técnica ONU. 1988. Manual de Técnicas de Diagnóstico Virológico.

Felsenstein J. 1993. PHYLIP (Phylogeny Inference Package) version $3.5 \mathrm{c}$. Distributed by the author. University of Washington Department of Genetics, Seattle, Wash.

Hamers CB, B Couvreur, C Dehan, C Letellier, P Lewalle, P Pastoret, P Kerkhofs. 2000. Differences in experimental virulence of bovine viral diarrhea viral strains isolated from hemorrhagic syndromes. Vet J 160, 250-258.

Houe H. 1999. Epidemiological features and economical importance of bovine virus diarrhea virus (BVDV) infections. Vet Microbiol 64, 89-107.

Kobrak A, EL Weber. 1997. Bovine diarrhea virus: an update. Rev Argent Microbiol 29, 47-61.

Meyers G, N Tautz, R Stark, J Brownlie, EJ Dubovi, MS Collett, HJ Thiel. 1992. Rearrangement of viral sequences in cytopathogenic pestiviruses. Virology 191, 368-86.

Muñoz DP, IA Lager, S Mersich, O Zabal, E Ulloas, AA Schudel, EL Weber. 1996. Fetal infections with Bovine Viral Diarrhea Virus in Argentina. Br Vet J 152, 175-182.

Occhi H, S Alenius, M Scortti, F Deicas, B Santiroco, J Daffner. 1991. Prevalencia de anticuerpos contra el virus de la Diarrea Viral Bovina (BVD) en pool de leche en rodeos de la cuenca lechera santafesina. XII Reunión de Soc. Arg. Virología. Buenos Aires. Argentina.

Odeon AC, CL Kelling, DJ Marshall, ES Estela, EJ Dubovi, RO Donis. 1999. Experimental infection of calves with bovine viral diarrhea virus genotype II (NY-93). $J$ Vet Diagn Invest 11, 221-228.
Page RDM. 1996. Treeview: An application to display phylogenetic trees on personal computers. Computer Applications in the Biosciences 12, 357-358.

Pellerin C, Van Den Hurk J, Lecomte J, Tussen P. 1994. Identification of a new group of bovine diarrhea virus strains associated with severe outbreaks and high mortalities. Virology 203, 260-268.

Rebhun WC, TW French, JA Perdrizet, EJ Dubovi, SG Dill, LF Karcher. 1989. Thrombocytopenia associated with acute bovine virus diarrhea infection in cattle. $J$ Vet Intern Med 3, 42-46.

Ridpath JF, JD Neill, M Frey, JG Landgraf. 2000. Phylogenetic, antigenic and clinical characterization of type 2 BVDV from North America. Vet Microbiol 77, 145-155.

Thompson JD, TJ Gibson, F Plewniak, F Jeanmougin, DG Higgins. 1997. The Clustal_X windows interface: flexible strategies for multiple sequence alignment aided by quality analysis tools. Nucleic Acids Research 25, 4876-4882.

Toplak I, T Sandvik, D Barlic-Maganja, J Grom, DJ Paton. 2004. Genetic typing of bovine viral diarrhoea virus: most Slovenian isolates are of genotypes $1 \mathrm{~d}$ and 1f. Vet Microbiol 99, 175-85.

Wakeley PR, JL Turner, G Ibata, DP King, T Sandvik, P Howard, TW Drew. 2004. Characterisation of a type 2 bovine viral diarrhoea virus isolated from cattle in the UK. Vet Microbiol 102, 19-24.

Wolfmeyer A, G Wolf, M Beer, W Strube, HR Hehnen, N Schmeer, OR Kaaden. 1997. Genomic (5' UTR) and serological differences among German BVDV field isolates. Arch Virol 142, 2049-2057. 